\title{
An adverse event in a well-established cervical cancer screening program: an observational study of 19,000 females unsubscribed to the program
}

This article was published in the following Dove Press journal:

Journal of Healthcare Leadership

27 October 2016

Number of times this article has been viewed

\author{
Mette Bach Larsen' \\ Hans Svanholm ${ }^{1,2}$ \\ Berit Andersen' \\ 'Department of Public Health \\ Programmes, ${ }^{2}$ Department of \\ Pathology, Randers Regional Hospital, \\ Randers, Denmark
}

Introduction: In Denmark, an organized approach to cervical cancer screening has had national coverage since 1998. However, in 2013, it was discovered that 19,000 females had been unsubscribed from the Danish National Cervical Cancer Screening Program and had thus not received invitations or reminders as recommended by the health authorities. The study aims to report the essence of this adverse event and describe the outcomes of reestablishing invitations in terms of participation rates and screening results. Furthermore, patient compensations to affected females diagnosed with cervical cancer and coverage in the mass media was reported. Methods: An observational study based on information from the Danish Pathology Databank, the Department of Public Health Programs, and Infomedia (a Danish database of media coverage) was carried out.

Results: A total of 19,106 females were affected. Of those still in the screening age, $37.7 \%$ had been tested within 3 years or 5 years despite not receiving any invitation. A total of $21.6 \%$ reconfirmed their status as unsubscribed. Of the remaining females, 55.6\% were tested within a year, and $94.6 \%$ of these test results were normal. Among females aged $>64$ years, $12.7 \%$ accepted the offer of a final screening test. Totally, $90 \%$ of these tests were normal. Nineteen females diagnosed with cervical cancer were compensated by the Danish Patient Compensation Association with a total of $€ 693,000$, ranging from $€ 8,900$ to $€ 239,700$. Coverage of cervical cancer screening in the mass media increased from 25 items in the 3 months prior to this adverse event to 590 items in the month when it became public.

Conclusion: Even though more than one-third of the affected females were tested despite not receiving regular invitations to participate in the screening program, lacking invitations were ranked alongside other adverse events in the health care system if cancer diagnoses were delayed.

Keywords: adverse event, mass screening, uterine cervical neoplasms

\section{Introduction}

The purpose of screening programs for cervical cancer uteri (CCU) is to identify CCU precursors at an early stage, enabling cone biopsy and preventing the development of the disease. ${ }^{1}$ Countries with organized CCU screening programs have lower prevalence and have seen larger mean decreases in $\mathrm{CCU}$ incidence and mortality compared to countries without such organized programs. ${ }^{2}$ Moreover, organized cancer screening programs are cost-effective alternatives to opportunistic programs. ${ }^{1}$

In CCU screening, it is crucial to have a high coverage of the target population to reach adequate efficiency. To secure high testing rates at recommended time intervals, invitations and reminders are regularly forwarded to females in the target population. In Denmark, an organized approach to CCU screening had gradually been rolled out
Correspondence: Mette Bach Larsen Department of Public Health Programmes, Randers Regional Hospital, Skovlyvej I, DK-8930 Randers NØ, Denmark

Tel +4578420265

Fax +4578424345

Email metbacla@rm.dk
Journal of Healthcare Leadership 2016:8 6I-69

61

(c) (i) (5) 2016 Larsen et al. This work is published and licensed by Dove Medical Press Limited. The full terms of this license are available at https://www.dovepress.com/terms.

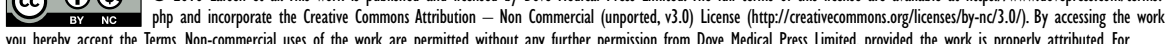
permission for commercial use of this work, please see paragraphs 4.2 and 5 of our Terms (https://www.dovepress.com/terms.php). 
from the 1960s until full coverage in $1998 . .^{3,4}$ The overall coverage of the organized screening program was $75.6 \%$ with a participation rate of $64.1 \%$ within 365 days after invitation. In 2013, it was discovered that 19,000 females had been unsubscribed from the Danish National Cervical Cancer Screening Program (NCCSP) and had thus not received invitations or reminders as recommended by the health authorities.

The study aims to report the essence of this adverse event and describe the outcomes of reestablishing invitations in terms of participation rates and screening results. Furthermore, patient compensations to affected females diagnosed with CCU and coverage in the mass media was reported.

\section{Methods}

\section{Setting}

In 2007, 14 Danish counties were merged into five regions of which Central Denmark Region (CDR) is the second largest. CDR covers $\sim 22 \%$ of the total Danish population corresponding to almost 1.3 million inhabitants (January 1, 2015). ${ }^{5}$

CCU screening practice varied between counties until national recommendations were updated in 2007 and practices were harmonized. Females aged 23-49 years are now invited to participate every third year and females aged 50-64 years every fifth year. Invitations are followed by up to two reminders if not tested within 90 days or 180 days after the initial invitation. ${ }^{6}$ Invitations and reminders are personal and sent by mail reminding the female to contact her family physician (FP), who will collect a cervical cytology. Today, females can unsubscribe to the NCCSP by contacting the Department of Public Health Programs (DPHP) by telephone or secure email, or they can unsubscribe via the Internet, if they do not wish to participate or for other reasons, eg, total hysterectomy. Until 2008, it was only possible for health professionals or administrative personnel to register unsubscriptions, and this was managed locally in each county with no knowledge of participation or unsubscriptions in other counties. In 2007, a national invitation module (IM) was embedded in the Danish National Pathology Data Bank (DPB) where all pathological tests, including cervical cytologies, are stored. ${ }^{7}$ Information about screening history and possible unsubscriptions was transferred from the previous local systems into the IM.

Alongside the organized screening program, opportunistic testing is widespread in Denmark ${ }^{8}$ and can be initiated by either a physician or the female herself. Both screening tests and opportunistic tests are free of charge in Denmark.

\section{Description of the adverse event}

In 2010, administration of the NCCSP in the CDR became centralized at DPHP. The staff observed that some females contacted the DPHP because they did not receive invitations for CCU screening. Often these females were registered as unsubscribed with a system code instead of the expected initials of the person who had registered the unsubscription; moreover, these females seemed to be unaware that they were unsubscribed from the program. In 2013, the suspicion of a systematic error was established, and to underpin the significance of the observations, a random sample of 60 females unsubscribed with the system code was identified. Of these, 24 (40\%) females were registered in DPB with total hysterectomy and were thus correctly unsubscribed. The remaining 36 females were asked if they were aware of their status as having unsubscribed to the NCCSP. Twentyseven females answered, of which 26 females wished to be reassigned to the program. None of the responding females were aware that they were registered as unsubscribers. A thorough investigation was initiated, and it was found that a disproportionate number of the unsubscriptions were found in connection with continuing modernizations of the technical management of the screening program and in connection with the data transformation into the IM. It was thus concluded that the females were unsubscribed due to administrative errors.

\section{Identification and classification of affected females}

All females unsubscribed from the screening program with the system code were identified in the IM on October 13, 2013. If they were registered with total hysterectomy, they were considered to be correctly unsubscribed. Information on total hysterectomy was retrieved from the Danish National Patient Registry (Table S1). ${ }^{9,10}$

It was verified whether females in the screening age had had a cervical cytology within the past 3 years (among 23- to 49-year olds) or 5 years (among 50- to 64-year olds). Cervical cytologies were identified in the DPB (material type 23: cervical/vaginal cytologies).

Finally, information on any CCU diagnosis was retrieved from the Danish Cancer Registry. ${ }^{11}$

The study was approved by the Danish Data Protection Agency (journal number: 2007-58-0010/1-16-02-475-15). According to Danish Legislation and the Central Denmark Region Committees on Biomedical Research Ethics, registerbased studies do not need formal ethical approval or patient written informed consent. 
Initiatives after identification of the adverse event In October 2013, DPHP launched three initiatives to rectify the adverse event. First of all, females still in the screening age were reassigned to the program if they were not registered with a total hysterectomy or CCU diagnosis. Further, if they were not registered with a cervical cytology within the past 3 years (23- to 49-year olds) or 5 years (50- to 64-year olds), they received a letter with information about the adverse event and a recommendation to contact their FP to be tested. As recommended in the NCCSP guidelines, the females received up to two reminders after 90 days and 180 days. Second, females older than 64 years received a letter informing about the adverse event and were recommended to contact their FP for a final screening test, which would be analyzed for highrisk human papillomavirus (hrHPV), which at the time was about to become the primary screening method for females older than 60 years. ${ }^{6}$ These females received no reminders since they were already outside the target population of the NCCSP. Finally, females registered with a diagnosis of CCU after the date of the unsubscription were personally notified about the adverse event and the possibility to report any injury to the Danish Patient Compensation Association. ${ }^{12}$

Normally, there is a 10-year statute of limitation to report injuries to the Danish Patient Compensation Association. However, in March 2014, the government passed a new law to securing females affected by this adverse event the possibility to report their injuries even though the 10-year statute of limitation was exceeded.

In addition to the direct communication between the authorities and the affected females, the mass media covered the issue nationally in television, newspapers, and online media.

\section{Data collection for follow-up on initiatives}

To describe the outcomes of reestablishing invitations to females who had been unsubscribed from the screening program, information on new unsubscriptions and reasons for unsubscription were collected from the IM.

Number and result of cervical cytology were collected from the DPB. The results of cytologies were classified according to Bethesda classification (Table S1). ${ }^{13}$ Since carcinoma is a rare outcome, high-grade squamous intraepithelial lesion (HSIL) and carcinoma were reported as one category (HSIL+) to protect the anonymity of those diagnosed with carcinoma. These data were obtained 1 year after the reassignment of the females ( 6 months after the last reminder). Analyses for hrHPV were performed at the Department of Pathology at the Randers Regional Hospital by the use of cobas $^{\circledR} 4800$ human papillomavirus (HPV) DNA test
(Hoffman-La Roche Ltd, Basel, Switzerland; Table S1). ${ }^{14}$ These data were collected on September 30, 2014 (6 months after the females were notified).

The Danish Patient Compensation Association makes decisions on compensation claims for patients injured in connection with treatment in the Danish health care system. If a compensation claim is rejected, patients can appeal to the National Agency for Patients' Rights and Complaints. The responsible department reports information about the cases to the Danish Patient Compensation Association and are informed directly about the adjudications. Thus, information on the number of females diagnosed with CCU-reporting injuries, adjudications, and the size of the compensations was continuously collected at the DPHP. This study reports the status on adjudications by April 1, 2016.

Coverage of the adverse event in the mass media was retrieved from Infomedia, which is a media monitoring service covering traditional print media, web media, radio, and television. ${ }^{15}$ The search terms used were cervical cancer and screening, and both words were to appear. The time frame for the search was from July 1, 2013, to March 31, 2014. All retrieved items were hand searched for relevance by the corresponding author.

\section{Analyses}

Outcomes of reassigning females to the program (reestablished unsubscriptions, test activity, and test results) and offering females older than 65 years a final screening test (test activity and test results) are presented along with adjudications (recompensed/rejected) and compensations (total amount/min-max/mean in Danish krone and euros rounded off to the nearest hundred).

Differences were tested using a Pearson's chi-squared test. Statistical significance was defined as a $P$-value of $<0.05$. Stata SE 13 (StataCorp LP, College Station, TX, USA) was used for all data analyses.

\section{Results}

A total of 19,106 females alive on October 13, 2013, were identified as being unsubscribed from the screening program; $10,094(52.8 \%)$ were in the screening age (23-64 years). Of these, $3,804(37.7 \%)$ had been tested within 3 years (23- to 49-year olds) or 5 years (50- to 64-year olds) despite receiving no invitation. Another 189 (1.9\%) had been diagnosed with cervical cancer or carcinoma in situ. Thus, this study reports on 6,101 females (Figure 1). Of these, 1,318 (21.6\%) females actively reconfirmed their unsubscription to the program within 1 year, mainly because they did not want to participate $(72.9 \%)$ or had had a total hysterectomy that was not found 


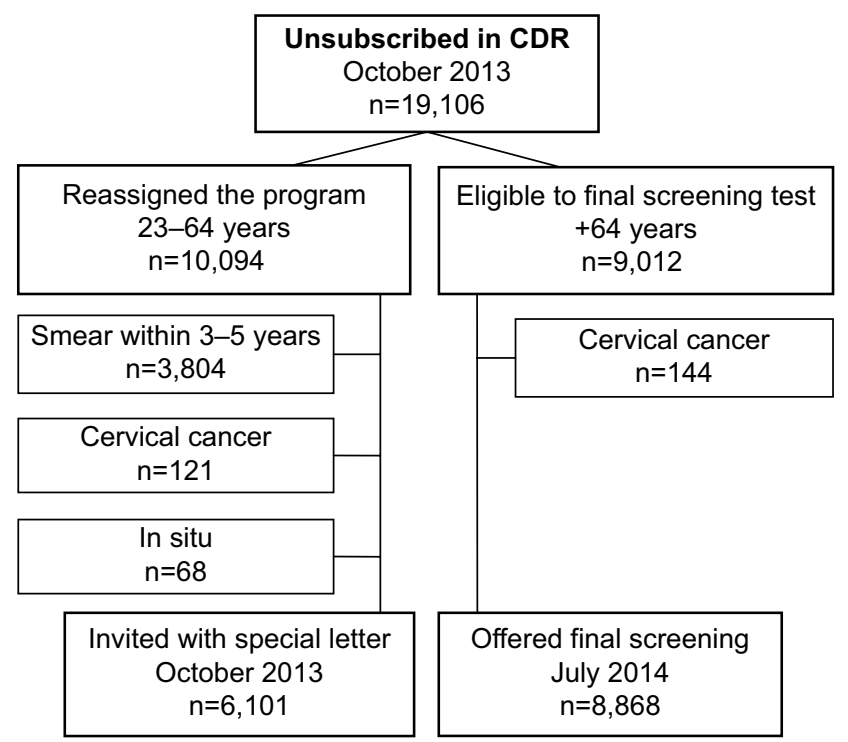

Figure I Identification of affected females in the CDR. Abbreviation: CDR, Central Denmark Region. in the Danish National Patient Registry (24.8\%). The remaining 4,783 had been unsubscribed from the NCCSP between 5.8 years and 32.7 years for a mean of 13.1 years (Table 1).

Of the unsubscribed females, 9,012 (47.2\%) were aged 65 years or older and thus no longer in the screening population; 144 (1.6) of these females had a CCU diagnosis. A total of $8,868(98.4 \%)$ females received a letter informing about the adverse event (Figure 1). These females had been unsubscribed from the program between 5.8 years and 32.8 years for a mean of 15.3 years (Table 2).

\section{Outcome of cytologies among females in the screening age}

Of the 4,783 females, a total of 2,660 (55.6\%) were tested within 1 year. Participation rates ranged from $52.4 \%$ among the 55 - to 64 -year olds to $58.6 \%$ among females younger than 45 years $(P=0.001$; Table 1$)$.

Table I Test activity and results for 4,783 unsubscribed females (23-64 years) reassigned to the screening program

\begin{tabular}{|c|c|c|c|c|c|}
\hline \multirow{2}{*}{$\begin{array}{l}\text { Age } \\
\text { Total }\end{array}$} & \multicolumn{2}{|l|}{$\begin{array}{l}\text { Number of years } \\
\text { unsubscribed }\end{array}$} & \multirow[t]{2}{*}{$\begin{array}{l}\text { Tested after reassignment, } \\
\text { n (\% of reassigned) }\end{array}$} & \multicolumn{2}{|c|}{$\begin{array}{l}\text { Result of cytology, n } \\
\text { (\% of tested) }\end{array}$} \\
\hline & & & & & \\
\hline \multirow[t]{7}{*}{$23-64$ years $(n=4,783)$} & Range & $5.8-32.7$ & $2,660(55.6)$ & Normal & $2,516(94.6)$ \\
\hline & Mean & 13.1 & & ASCUS & $65(2.4)$ \\
\hline & Median & 13.0 & & ASC-H & $26(1.0)$ \\
\hline & & & & AGC & $4(0.2)$ \\
\hline & & & & LSIL & $14(0.5)$ \\
\hline & & & & HSIL $+^{\mathrm{a}}$ & $26(1.0)$ \\
\hline & & & & Inadequate & $9(0.3)$ \\
\hline \multicolumn{6}{|l|}{ Age groups } \\
\hline \multirow[t]{7}{*}{$<45$ years $(n=1,457)$} & Range & $5.8-26.5$ & $854(58.6)$ & Normal & 802 (93.9) \\
\hline & Mean & 11.8 & & ASCUS & $25(2.9)$ \\
\hline & Median & 11.3 & & ASC-H & $6(0.7)$ \\
\hline & & & & AGC & $\mathrm{I}(0.1)$ \\
\hline & & & & LSIL & $7(0.8)$ \\
\hline & & & & $\mathrm{HSIL}+^{\mathrm{a}}$ & $13(1.5)$ \\
\hline & & & & Inadequate & $0(0)$ \\
\hline \multirow[t]{7}{*}{$45-54$ years $(n=l, 457)$} & Range & $6.0-32.5$ & $826(56.7)$ & Normal & $778(94.2)$ \\
\hline & Mean & 13.4 & & ASCUS & $27(3.3)$ \\
\hline & Median & 13.2 & & ASC-H & $5(0.6)$ \\
\hline & & & & AGC & $3(0.4)$ \\
\hline & & & & LSIL & $4(0.5)$ \\
\hline & & & & $\mathrm{HSIL}+^{\mathrm{a}}$ & $7(0.9)$ \\
\hline & & & & Inadequate & $2(0.2)$ \\
\hline \multirow[t]{7}{*}{$55-64$ years $(n=1,869)$} & Range & $5.8-32.7$ & $980(52.4)$ & Normal & $936(95.5)$ \\
\hline & Mean & 13.9 & & ASCUS & $13(1.3)$ \\
\hline & Median & 13.7 & & ASC-H & $15(1.5)$ \\
\hline & & & & AGC & $0(0)$ \\
\hline & & & & LSIL & $3(0.3)$ \\
\hline & & & & $\mathrm{HSIL}+^{\mathrm{a}}$ & $6(0.6)$ \\
\hline & & & & Inadequate & $7(0.7)$ \\
\hline
\end{tabular}

Notes: A total of 6,101 females were informed about the adverse event. Of these, 1,318 reconfirmed their wish not to be part of the screening program. Test activity is reported for the remaining 4,783. ${ }^{\mathrm{HSSIL}}$ and carcinoma.

Abbreviations: ASCUS, atypical squamous cells of undetermined significance; ASC-H, atypical squamous cells - cannot exclude HSIL; AGC; atypical glandular cells of undetermined significance; LSIL, low grade squamous intraepithelial lesion; HSIL, high grade squamous intraepithelial lesion. 
Table 2 Test activity and results for 8,868 females (64+ years) offered a final screening test analyzed for hrHPV

\begin{tabular}{|c|c|c|c|c|c|}
\hline $\begin{array}{l}\text { Age } \\
\text { Total }\end{array}$ & \multicolumn{2}{|c|}{$\begin{array}{l}\text { Number of years } \\
\text { unsubscribed }\end{array}$} & $\begin{array}{l}\text { Accepting final screening, } \\
\mathbf{n}(\% \text { of offered) }\end{array}$ & \multicolumn{2}{|c|}{ Result of hrHPV test ${ }^{a}, n$ ( $\%$ of tested) } \\
\hline \multirow{4}{*}{$64+$ years $(n=8,868)$} & Range & $5.8-32.8$ & $\mathrm{I}, 124$ (12.7) & Normal & $\mathrm{I}, 012(90.0)$ \\
\hline & Mean & 15.3 & & HPV I6/18 & $12(1.1)$ \\
\hline & Median & 15.0 & & HPV other types ${ }^{b}$ & $47(4.2)$ \\
\hline & & & & HPV not performed & $53(4.7)$ \\
\hline \multicolumn{6}{|l|}{ Age groups } \\
\hline \multirow[t]{4}{*}{$65-69$ years $(n=2,892)$} & Range & $5.8-32.5$ & $592(20.5)$ & Normal & $549(92.7)$ \\
\hline & Mean & 13.9 & & HPV I6/18 & $8(1.4)$ \\
\hline & Median & 13.7 & & HPV other types ${ }^{\mathrm{a}}$ & $27(4.6)$ \\
\hline & & & & HPV not performed & $8(1.4)$ \\
\hline \multirow[t]{4}{*}{$70-74$ years $(n=2,058)$} & Range & $6.1-32.6$ & $339(16.5)$ & Normal & $315(92.9)$ \\
\hline & Mean & 15.3 & & HPV $16 / 18$ & $2(0.6)$ \\
\hline & Median & 14.6 & & HPV other types ${ }^{\mathrm{a}}$ & $15(4.4)$ \\
\hline & & & & HPV not performed & $7(2.1)$ \\
\hline \multirow[t]{4}{*}{$75-79$ years $(n=I, 367)$} & Range & $6.1-32.0$ & $103(7.5)$ & Normal & $96(93.2)$ \\
\hline & Mean & 16.6 & & HPV I6/I8 & $2(1.9)$ \\
\hline & Median & 15.3 & & HPV other types ${ }^{\mathrm{a}}$ & $3(2.9)$ \\
\hline & & & & HPV not performed & $2(1.9)$ \\
\hline \multirow[t]{4}{*}{$80+$ years $(n=2,55 \mathrm{I})$} & Range & $6.5-32.8$ & $90(3.5)$ & Normal & $52(57.8)$ \\
\hline & Mean & 16.4 & & HPV I6/I8 & $0(0)$ \\
\hline & Median & 15.5 & & HPV other types ${ }^{\mathrm{a}}$ & $2(2.2)$ \\
\hline & & & & HPV not performed & $36(40.0)$ \\
\hline
\end{tabular}

Notes: ${ }^{a}$ Tests analyzed outside CDR were not analyzed for hrHPV. bhrHPV types 3I, 33, 35, 39, 45, 5I, 52, 56, 58, 59, 66, and 68.

Abbreviations: hrHPV, high-risk human papillomavirus; HPV, human papillomavirus.

Among the 2,660 cytologies, 2,516 (94.6\%) were normal and $26(1 \%)$ were HSIL+. The number of normal cytologies ranged from $93.9 \%$ among females younger than 45 years to $95.5 \%$ among females older than 55 years $(P=0.002)$. The results of HSIL+ ranged from $0.6 \%$ among females older than 55 years to $1.5 \%$ among females younger than 45 years $(P=0.002$; Table 1$)$.

\section{Outcome of hrHPV testing of females older than 64 years}

Among the 8,868 females older than 64 years, a total of 1,124 (12.7\%) females were tested. Testing activity decreased with older age, ranging from $20.5 \%$ for females aged $65-69$ years to $3.5 \%$ for females older than 80 years $(P<0.001)$.

In all ages, $>90 \%$ of the tests were hrHPV negative. The proportion of females testing positive for HPV (16 or 18 ) was highest in the age groups $65-69$ years $(1.4 \%)$ and $75-79$ years $(1.9 \%$; Table 2$)$.

\section{Reported patient injuries and adjudications}

By April 1, 2016, 85 complaints from females diagnosed with CCU had been processed in the Danish Patient Compensation Association. Initially, the Danish Patient Compensation
Table 3 Overview of 85 injuries reported to the Danish Patient Compensation Association, adjudications and compensations.

\begin{tabular}{ll}
\hline Adjudication & $\mathbf{N}(\%)$ \\
\hline Rejected & $66(77.6)$ \\
Compensated $^{\mathrm{a}}$ & $19(22.4)$ \\
Compensations & Amount $\left(\mathrm{DKK} / €^{\mathrm{b}}\right)$ \\
Total & $5,197,462 / 693,000$ \\
Min-max & $66,415-1,797,943 / 8,900-239,700$ \\
Mean & $273,551 / 36,500$ \\
\hline
\end{tabular}

Notes: ancluding two cases that were rejected in the Danish Patient Compensation Association and reversed by the National Agency for Patients' Rights and Complaints. ${ }^{\mathrm{b}}$ Rounded off to the nearest 100.

Abbreviations: DKK, Danish krone; $€$, euro; Min-max, minimum-maximum.

Association rejected 68 complaints of which eight were appealed to the National Agency for Patients' Rights and Complaints, which reversed two. Thus, 19 females were compensated with a total of $€ 693,000$, ranging from $€ 8,900$ to $€ 239,700$ (Table 3).

The reasons given for not granting compensations were that the females had not previously responded to invitations to the screening program or that the disease was either at an early stage or so progressive that it was unlikely that screening 3-5 years earlier would have detected CCU precursors or changed the course of the disease. 


\section{Mass media}

A total of 1,186 hits were retrieved from Infomedia, 436 (36.8\%) from traditional written sources and 750 (63.2\%) from web sources. Of these, $53(4.5 \%)$ were excluded because Infomedia could not show the items and $72(6.1 \%)$ were excluded because they were not regarding CCU screening. Thus, a total of 377 (86.5\%) written sources and 684 (91.2\%) web sources were included.

As illustrated in Figure 2, 25 items were retrieved in the 3 months prior to October 2013 when the adverse event became public. These items mainly regarded the HPV vaccination and one celebrity patient history. In October, November, and December, there were 698 items, of which 590 were retrieved in October. The first items regarded information about the adverse event and politicians at both regional and national levels was involved. Later, items regarding the risk of similar adverse events in other screening programs, the possibility of affected females to be awarded compensation, and handling of cases where the 10-year statute of limitation might be exceeded became dominant topics. Finally, the participation rate of $65 \%$ in the NCCSP was highlighted, and few sources mentioned the female's own responsibility in getting the cervical cytology. In November and December, the main topic concerned the first compensations granted. From January to March 2014, 338 items were retrieved, which peaked in March, when the new law was established to secure the possibility for patients to report injury to the Danish Patient Compensation Association even though the ten-year statute of limitation was exceeded. From November to March, the consequences of the adverse event in terms of missed cancers and deaths caused by CCU in unsubscribed females were ongoing (Figure 2).

\section{Discussion}

This unique observational study reports a rare adverse event where females in a CCU screening program were unsubscribed from the program due to administrative errors. After reestablishing invitations, a total of $55.6 \%$ females in the screening age (23-64 years), who did not actively reconfirm their unsubscription, were tested within a year, and the results were normal in $94.6 \%$ of the tests. Among those older than 64 years, $12.7 \%$ accepted the offer of a final screening test; $90 \%$ of these tests were normal. A total of 19 females diagnosed with CCU were recompensed by the Danish Patient Compensation Association with amounts ranging from $€ 8,900$ to $€ 239,700$. Coverage of CCU screening in the mass media increased from 25 items in the 3 months prior to this adverse event to 590 items in the month when the adverse event became public.

Lessons learned from this study are unique in trying to understand the dynamics of screening patterns within an organized and well-established screening program. Furthermore, the identification of affected females and the outcomes of the initiatives to correct and compensate for the adverse event are from well-established registries with high validity.,10,11

The study also has several limitations. Thus, a relatively high number of females older than 64 years had their sample analyzed by cytology instead of hrHPV as recommended. The reason for this limitation was that their specimens were obtained and analyzed outside CDR. Further, affected

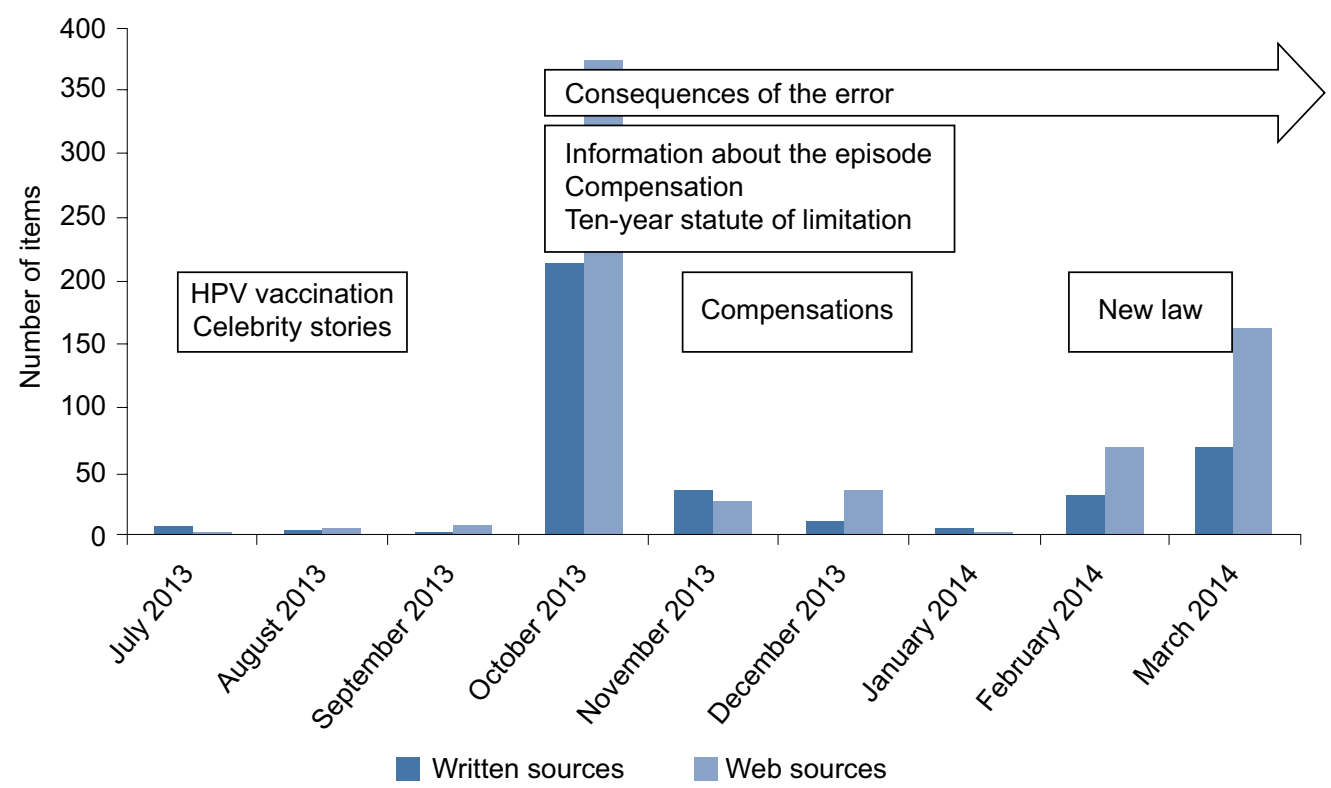

Figure 2 Coverage of cervical cancer screening in the mass media from July 2013 to March 2014 . Abbreviation: HPV, human papillomavirus. 
females were identified as those unsubscribed by the special system code and are as such correct. However, if females were to be identified as females unsubscribed due to administrative errors, there was some degree of misclassification. The fact that $>20 \%$ of the females still in the screening age actively reconfirmed their unsubscription within 1 year indicates that not all of those listed as unsubscribed were the result of administrative errors. This is further supported by the fact that the participation rate was $55.6 \%$ among these females compared to $64.1 \%$ in the NCCSP. ${ }^{16}$ If all females were unintendedly unsubscribed, it could be expected that the participation rate among these females would be higher due to the extended screening interval and the massive focus on the consequences of lacking CCU screening in the mass media. This has been seen in the UK after the massive mass media coverage of a CCU death of a young celebrity. ${ }^{17}$

The results of the cytologies among females younger than 45 years are in line with a previous Danish study of the cytology results in females younger than 49 years screened after invitation. ${ }^{8}$ In that study, $93 \%$ of the cytology results showed normal cells compared to $93.9 \%$ in this study. However, slightly more females had HSIL+ in this study than in the group of females screened after invitation (1.5\% vs $1 \%)$.

The observational design of this study precludes any conclusions regarding the effect of the NCCSP. However, the fact that more than one-third of the unsubscribed females aged between 23 years and 64 years were tested without invitation indicates that the screening program is running in parallel with opportunistic testing. A Danish study has shown that even with a well-established screening program, one-fourth of all cervical cytologies among females aged 23-49 years are collected opportunistically. ${ }^{8}$ Most likely, both FPs and the females themselves are often aware of the benefits of regular cervical cytologies and request these regardless of the invitations.

It has been argued that the screening age in the NCCSP should be increased to include females aged 65 years and older. ${ }^{18}$ However, an important consideration in this debate is the participation rate among the older females. In this study, the participation rate was $20.5 \%$ among females aged 65-69 years and decreased further with older age. Even though this study cannot predict participation among older females if invited regularly, it may indicate that the participation rate is an important consideration for the costeffectiveness of the program if the screening age is expanded. Further studies are needed to clarify this.

The fact that the affected females were recompensed by the Danish Patient Compensation Association and a new law was established to suspend the 10-year statute of limitation indicates that lacking invitations to screening is ranked alongside other adverse events in the Danish health care system. This was also clear in the coverage of the adverse event in the mass media, where only few and no official sources mentioned the female's own responsibility in complying with the NCCSP. Furthermore, the massive interest in the matter reflects that also in the public opinion, the cervical cancer screening program has been accepted as an integrated part of the services that the health care system provides.

\section{Conclusion}

Cervical cytologies to prevent CCU seem to be an integrated part of the health care services offered in Denmark. Not receiving regular invitations to participate in the screening program calls upon considerable coverage in the mass media and is ranked alongside other adverse effects in the health care system if cancer diagnoses are delayed.

\section{Acknowledgment}

Stephanie Frausing Knudsen contributed to the manuscript by collecting data about patient injuries and adjudications.

\section{Disclosure}

The authors report no conflicts of interest in this work.

\section{References}

1. International Agency for Research on Cancer. IARC Handbooks of Cancer Prevention Volume 10. Cervix Cancer Screening. Lyon: IARC Press; 2005.

2. Bray F, Loos AH, McCarron P, et al. Trends in cervical squamous cell carcinoma incidence in 13 European countries: changing risk and the effects of screening. Cancer Epidemiol Biomarkers Prev. 2005;14(3):677-686.

3. Bigaard J, Hariri J, Lynge E. Cervical cancer screening in Denmark. Eur J Cancer. 2000;36(17):2198-2204.

4. Lynge E, Clausen LB, Guignard R, Poll P. What happens when organization of cervical cancer screening is delayed or stopped? J Med Screen. 2006;13(1):41-46.

5. Statistics Denmark. Statistical Yearbook 2015. Copenhagen: Rosendahls; 2015 .

6. Danish Health and Medicines Authority. Screening for livmoderhalskrceft-anbefalinger [Cervical Cancer Screening - Recommendations]. Copenhagen: Danish Health and Medicines Authority; 2012.

7. Bjerregaard B, Larsen OB. The Danish Pathology Register. Scand J Public Health. 2011;39(7 suppl):72-74.

8. Tranberg M, Larsen MB, Mikkelsen EM, Svanholm H, Andersen B. Impact of opportunistic testing in a systematic cervical cancer screening program: a nationwide registry study. BMC Public Health. 2015;15:681.

9. Lynge E, Sandegaard JL, Rebolj M. The Danish National Patient Register. Scand J Public Health. 2011;39(7 suppl):30-33.

10. Schmidt M, Schmidt SA, Sandegaard JL, Ehrenstein V, Pedersen L, Sorensen HT. The Danish National Patient Registry: a review of content, data quality, and research potential. Clin Epidemiol. 2015;7:449-490

11. Gjerstorff ML. The Danish cancer registry. Scand J Public Health. 2011;39(7 suppl):42-45. 
12. Patienterstatningen [The Danish Patient Compensation Association] [homepage on the Internet]. Available from: http://patienterstatningen. dk/. Accessed April 18, 2016. Danish.

13. Nayar R, Wilbur DC, editors. The Bethesda System for Reporting Cervical Cytology. Definitions, Criteria, and Explanatory Notes. 3rd ed. Switzerland: Springer International Publishing; 2015.

14. Rao A, Young S, Erlich H, et al. Development and characterization of the Cobas human papillomavirus test. J Clin Microbiol. 2013;51(5): 1478-1484.

15. Infomedia [homepage on the Internet]. Available from: http://infomedia. dk/. Accessed April 18, 2016.
16. Dansk Kvalitetsdatabase for Livmoderhalskræftscreening [Danish Quality Database for Cervical Cancer Screening]. Annual Report; 2014. Available from: https:/www.sundhed.dk/content/cms/82/4682_dkls\%C3\%A5rsrapport-2014_12-version_01-07-15_offentligg\%C3\%B8relse. pdf. Accessed April 7, 2016. Danish.

17. Marlow LAV, Sangha A, Patnick J, Waller J. The Jade Goody effect: whose cervical screening decisions were influenced by her story? J Med Screen. 2012;19(4):184-188.

18. Hammer A, Fuglsang K, Hogsbjerg K, Blaakaer J. Screening for cervical cancer in women older than 65 years will probably reduce the incidence and mortality. Ugeskr Laeger. 2015;177(23):V12140697. 


\section{Supplementary material}

Table SI Classification of total hysterectomy, cervical cytology, and hrHPV results

\begin{tabular}{|c|c|c|c|c|c|}
\hline Total hysterectomy & \multicolumn{2}{|l|}{ ICD8 } & \multicolumn{3}{|l|}{ ICDIO } \\
\hline ICD codes & \multicolumn{2}{|c|}{$\begin{array}{l}61020,61040,61050,61100,61780 \\
62300,72230,72240,72650\end{array}$} & \multicolumn{3}{|c|}{$\begin{array}{l}\text { KLCD00, KLCD0 I, KLCD04, KLCDI0, KLCDII, KLCD30, KLCD3I, } \\
\text { KLCD40, KLDCI3, KLDC20, KLDC23, KLCD96, KLCD97, KLEFO0B, } \\
\text { KLEFI3, KMCA33 }\end{array}$} \\
\hline Cervix cytology* & Normal & ASCUS, ASC-H, AGC & LSIL & HSIL+ & Inadequate \\
\hline SNOMED codes & $\begin{array}{l}M 00120 \\
M 00121 \\
M 00122\end{array}$ & $\begin{array}{l}M 67014 \\
M 67010 \\
M 67020\end{array}$ & M67016 & $\begin{array}{l}\text { M670I } 7 \\
\text { M80I02 } \\
\text { M8I402 } \\
\text { M80I03 } \\
\text { M80703 } \\
\text { M8I403 }\end{array}$ & M090IO \\
\hline hrHPV test** & HPVI6 & HPVI8 & Other hrHPV types*** & hrHPV negative & Inadequate \\
\hline SNOMED codes & $\begin{array}{l}\text { FY5006 } \\
\text { AE33416 }\end{array}$ & $\begin{array}{l}\text { FY5006 } \\
\text { ÆE33418 }\end{array}$ & $\begin{array}{l}\text { FY5009 } \\
\text { FY5010 }\end{array}$ & $\begin{array}{l}F Y 5001 \\
F Y 5003 \\
F Y 5005\end{array}$ & M0901H \\
\hline
\end{tabular}

Notes: *Bethesda; **Cobas 4800 results; ***HPV3I, 33, 35, 39, 45, 5I, 52, 56, 58, 59, 66, 68.

Abbreviations: hrHPV, high-risk human papillomavirus; ICD, International Classification of Diseases; ASCUS, atypical squamous cells of undetermined significance; ASC-H, atypical squamous cells - cannot exclude HSIL; AGC, atypical glandular cells of undetermined significance; LSIL, Low grade squamous intraepithelial lesion; HSIL+, high-grade squamous intraepithelial lesion/ carcinoma in situ/ adenocarcinoma in situ/ carcinoma/ planocellular carcinoma/ adenocarcinoma.

Journal of Healthcare Leadership

\section{Publish your work in this journal}

The Journal of Healthcare Leadership is an international, peer-reviewed, open access journal focusing on leadership for the health profession. The journal is committed to the rapid publication of research focusing on but not limited to: Healthcare policy and law; Theoretical and practical aspects healthcare delivery; Interactions between healthcare and society and evidence-based practices; 